\title{
The Role of Nutrition and Inflammation on Cognition in a High-Risk Group for Alzheimer's Disease
}

\author{
Jordan M. Jackson ${ }^{\mathrm{a}}$, Allison A. Bay ${ }^{\mathrm{b}}$, Jolie Denise Barter ${ }^{\mathrm{b}}$, Liang Ni ${ }^{\mathrm{b}}$, William Michael Caudle ${ }^{\mathrm{a}, \mathrm{c}}$, \\ Monica C. Serra ${ }^{\mathrm{d}, \mathrm{e}}$, Whitney Wharton ${ }^{\mathrm{f}}$ and Madeleine E. Hackney ${ }^{\mathrm{b}, \mathrm{f}, \mathrm{g}, \mathrm{h}, *}$ \\ ${ }^{a}$ Emory University's Rollins School of Public Health, Gangarosa Department of Environmental Health, Atlanta, \\ GA, USA \\ ${ }^{\mathrm{b}}$ Emory University School of Medicine Department of Medicine, Division of General Medicine and Geriatrics, \\ Atlanta, GA, USA \\ ${ }^{\mathrm{c}}$ Emory Center for Neurodegenerative Disease, Atlanta, GA, USA \\ ${ }^{\mathrm{d}}$ Division of Geriatrics, Gerontology \& Palliative Medicine, Department of Medicine, University of Texas Health \\ Science Center at San Antonio, San Antonio, TX, USA \\ e San Antonio Geriatrics Research, Education \& Clinical Center, South Texas Veterans Health Care System, San \\ Antonio, TX, USA \\ ${ }^{\mathrm{f}}$ Emory University School of Nursing, Atlanta, GA, USA

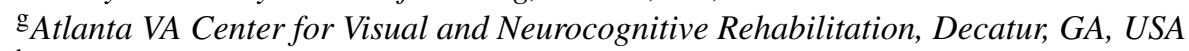 \\ ${ }^{\mathrm{h}}$ Emory University School of Medicine, Department of Rehabilitation Medicine, Atlanta, GA, USA
}

Accepted 22 July 2020

\begin{abstract}
. the need for more holistic approaches to mitigate AD-development risk. alpha

\footnotetext{
${ }^{*}$ Correspondence to: Madeleine E. Hackney, PhD, Associate Professor of Medicine, Department of Medicine, Emory University School of Medicine; Research Health Scientist, Atlanta VA Rehabilitation R\&D Center for Visual and Neurocognitive
}

Background: Alzheimer's disease (AD) is a prevalent neurodegenerative disease. Treatments are necessary to target people at high risk for $\mathrm{AD}$. Inflammation, particularly tumor necrosis factor alpha (TNF $\alpha)$, appears to be an important marker associated with the development of AD pathophysiology. Consuming a high-fat diet induces tissue expression of TNF $\alpha$.

Objective: This study investigates the relationship between nutrition, circulating inflammation, and cognition in African American women (age: $M=59.5$ ( \pm 8.20$)$ [42-73] years) at risk for developing AD.

Methods: Participants were split into high-fat and low-fat groups based on total dietary fat consumption self-reported on the Lower Mississippi Delta Nutrition Intervention Research Initiative Food Frequency Questionnaire (Delta NIRI FFQ).

Results: A high-fat diet was associated with increased blood serum $\mathrm{TNF} \alpha(p=0.02)$ compared to the low-fat diet. In addition, global cognition scores were $9.0 \%$ better in those who consumed a higher fat diet $(p=0.04)$. No significant differences across groups were noted for executive function, dual-tasking, and visuospatial performance.

Conclusion: These results indicate that there may be multiple biological pathways involved in AD development, suggesting

Keywords: African American, Alzheimer's disease, cognition, executive function, inflammation, nutrition, tumor necrosis

Rehabilitation, 1841 Clifton Rd. NE, \#553, Atlanta, GA 30329, USA. Tel.: +1 314412 4852; E-mails: mehackn@emory.edu; madeleine.hackney@va.gov 


\section{INTRODUCTION}

Alzheimer's disease (AD) is the 6th leading cause of death in the United States [1]. AD is a disorder that gradually and progressively destroys cognitive function. While the disease first affects declarative memory, it progresses to affect nondeclarative memory and ultimately leads to dementia [2]. AD has become more prevalent in recent years, and its prevalence is expected to increase. By 2050 it is predicted that one in 85 people world-wide will have $\mathrm{AD}$, including 13 million Americans [3, 4]. This increase in prevalence makes it imperative to develop better diagnostic measures and more efficient screening procedures for those in early stages of the disease $[5,6]$.

Ethnic minorities, female sex, and family history are aggravating factors of AD. The Alzheimer's Association estimates that the prevalence of $\mathrm{AD}$ and other dementias in African Americans (AA) above the age of 65 years is about twice the rate of older Whites [7]. Similarly, women are disproportionally affected by $\mathrm{AD}$. Women are two to three times more likely to develop AD than men [8] and are also more likely to become caregivers to AD patients. Genetic factors such as Apolipoprotein E ( $A P O E) \varepsilon 4$ allele increases the frequency of development of $\mathrm{AD}[9,10]$. Recent data shows that a higher percentage of AA have at least one copy of the $\varepsilon 4$ allele compared to European Americans [1]. Independent of genetic factors, those with a parental history of AD have a greater risk of developing dementia [11, 12]. Having one or both parents with dementia has been associated with greater cognitive impairment, thus contributing to disease severity [9]. Important next steps in investigating treatment for $\mathrm{AD}$ is to target individuals who are at a higher risk for $\mathrm{AD}$ and institute preventative strategies to provide early intervention [13].

Because ethnicity and biological sex cannot be changed, identifying modifiable risk factors in high risk groups is needed to reduce risk of cognitive decline and AD. One modifiable lifestyle factor that has received relatively little attention in the pathophysiology of $\mathrm{AD}$ is nutrition. In animal models, a high-fat (Western) diet has been shown to exacerbate AD-related pathology [14], but less is known in humans.

A high-fat diet can alter the immune system [15]. Alterations in the immune system could contribute to the pathophysiology of AD [16]. Elevated proinflammatory cytokines, particularly tumor necrosis factor alpha $(\mathrm{TNF} \alpha)$, are risk factors for the onset and progression of $\mathrm{AD}[17,18]$. On average, people with AD have higher levels of serum TNF $\alpha$ compared to healthy adults [19]. High levels of circulating TNF $\alpha$ correlate with poor performance on cognitive tasks [20]. Levels of TNF $\alpha$ expression can be altered with diet. A diet high in saturated fat increases the amount of $\mathrm{TNF} \alpha$ present in the plasma compared to a diet high in unsaturated fats [21]. In addition, production of pro-inflammatory cytokines is further augmented after an inflammatory stimulus in people with high trans-fat diets $[22,23]$. Currently unexplored is the relationship of a high-fat diet on characteristics of $\mathrm{AD}$, specifically in people who are predisposed for developing AD. This study included African American women who are predisposed for $\mathrm{AD}$ (have a parental history) to determine if individuals who consume a high-fat diet show early signs of memory deficits and systemic inflammation.

\section{MATERIALS AND METHODS}

\section{Study and participants}

The Institutional Review Board at Emory University School of Medicine and the Research and Development Committee of the Atlanta VA approved this work. Participants provided written informed consent before participating. Participants were recruited from the Emory Alzheimer's Disease Research Center from registries derived from previous studies of individuals with parental history of AD. Forty-two individuals were recruited for the study. Participants who completed less than half of the nutritional questionnaire $(n=11)$ and participants whose biomarker data was not completed $(n=5)$ were excluded from analyses resulting in a sample of 26 individuals. There were no significant differences between excluded and included participants on key demographics and clinical characteristics (Age (y): Included 59.5, Excluded 63.7; Education (y): Included 15.9; Excluded:16.3; BMI $\left(\mathrm{kg} / \mathrm{m}^{2}\right)$ : Included 30.6, Excluded 29.3; Number of falls (no.): Included 0.583, Excluded 0.3).

Participants were at least 40 years of age and selfidentified as African American (AA) and a woman. The participants' parents had a diagnosis of probable $\mathrm{AD}$ as defined by National Institute of Neurological Disorders and Stroke-Alzheimer's Disease and Related Disorders Association (NINDS-ADRDA) criteria, which was verified using the validated 
Dementia Questionnaire and medical records when available [24]. Because these women had a parent with likely $\mathrm{AD}$, these women were considered to be at greater risk for developing $\mathrm{AD}$.

\section{Nutrition data}

Lower Mississippi Delta Nutrition Intervention Research Initiative Food Frequency Questionnaire (Delta NIRI FFQ) was used to assess dietary habits because it highlighted the unique food, preparation, and portion sizes often consumed by AA adults from the Southern region [25]. Participants selfadministered the 158-item (short FFQ) Delta NIRI FFQ. Participants were instructed to report how often, on average, certain foods were consumed across the past year. This short FFQ was designed to include all foods on the longer FFQ, by collapsing similar foods to combine line items and simplifying adjustment questions and has been validated (Table 1) [26].

The Delta NIRI FFQ was used to categorize participants into low-fat or high-fat diets. Participants' self-reported dietary consumption habits were converted into an overall fat intake score based on dietary consumption frequency and portion sizes of 13 select high-fat food categories: 1) poultry and game (i.e., fried dark versus light meat), 2) beef and pork, 3) luncheon meat, sausage, hotdog, and eggs, 4) other meat (i.e., organ meat, ham hock), 5) fish (fried and fatty varieties), 6) vegetables (i.e., fried potatoes; fried onions), 7) mixed dishes, pizza, and pasta dishes, 8) milk (full versus low fat varieties), 9) nonbeverage dairy products (i.e., cheese, yogurt), 10) condiments (i.e., salad dressing, gravy), 11) dessert, sweets, and snacks (i.e., chips; nuts), 12) added fats (i.e., oils), and13) omega-3 fatty acid supplement. For each category, subjects were assigned a score of 0 (low fat) or 1 (high fat) based upon whether their intake was $\leq$ or $>$ the median intake of the group. All categories were summed to calculate an overall dietary fat intake score, with 0 representing the lowest fat intake and 13 representing the highest fat intake. Overall dietary fat intake scores of $\leq 6$ were considered "low-fat" and $>6$ were considered "high-fat".

To further clarify, food groups that are high in fat were assigned a score by assessing frequency of consumption and typical serving size consumed. Further, the food groups that we chose to evaluate were high in total fat, regardless of the type of fat.
Table 1

Food Grouping Used in Dietary Pattern Analysis

\begin{tabular}{|c|c|}
\hline Food Groups & Food Items \\
\hline Fried Potatoes/Onion & $\begin{array}{l}\text { French Fries, Fried Potatoes, } \\
\text { Potato Logs, Fried Onion Rings }\end{array}$ \\
\hline Poultry and Game & $\begin{array}{l}\text { Fried Chicken, "How often do you } \\
\text { eat the skin on the chicken" }\end{array}$ \\
\hline $\begin{array}{l}\text { Lunch Meat, Bacon, and } \\
\text { Eggs }\end{array}$ & $\begin{array}{l}\text { Hot Dogs, Sausage (non-breakfast } \\
\text { type), Ham, Bologna, Salami, } \\
\text { Potted Meat, Luncheon Meat, } \\
\text { Bacon, Breakfast Sausage, Eggs }\end{array}$ \\
\hline $\begin{array}{l}\text { Mixed Meat, Pizza, and } \\
\text { Pasta }\end{array}$ & $\begin{array}{l}\text { Mixed Dishes with Cheese } \\
\text { (Macaroni and Cheese, Lasagna, } \\
\text { Broccoli and Rice Casserole), Pizza }\end{array}$ \\
\hline Dairy & $\begin{array}{l}\text { Cottage Cheese, Cheese Spread } \\
\text { and Dips, Yogurt (Not Frozen) }\end{array}$ \\
\hline Beef and Pork & $\begin{array}{l}\text { Fried Beef, Pork (chops, roasts, } \\
\text { spareribs), "How often do you trim } \\
\text { the fat from the meat" }\end{array}$ \\
\hline Other Meat & $\begin{array}{l}\text { Neck bones, Ham Hock, Pig's Feet, } \\
\text { Liver }\end{array}$ \\
\hline Fish & $\begin{array}{l}\text { Fried Fish or Fish Sandwich } \\
\text { (including catfish), Sardines, } \\
\text { Maceral, Canned Salmon, Tuna } \\
\text { Salad, Tuna Casserole, }\end{array}$ \\
\hline Condiments & $\begin{array}{l}\text { Gravy, Salad Dressing (Regular, } \\
\text { Light, and Fat-Free), Mayonnaise }\end{array}$ \\
\hline Desserts, Sweets, and & Ice Cream, Pudding, Custard, \\
\hline Snacks & $\begin{array}{l}\text { Cheesecake, Doughnuts, Cookies, } \\
\text { Sweet Rolls, Muffins, Potato } \\
\text { Chips, Corn Chips, Cracklings, } \\
\text { Popcorn, Peanuts, Other Nuts, and } \\
\text { Peanut Butter }\end{array}$ \\
\hline Oils & $\begin{array}{l}\text { Stick Margarine, Soft Tub } \\
\text { Margarine, Butter, Salt Pork, } \\
\text { Bacon Fat, Olive Oil, Canola Oil, } \\
\text { Vegetable Oil }\end{array}$ \\
\hline Vitamins & Omega 3 Fatty Acids \\
\hline Other Beverages & Milk \\
\hline
\end{tabular}

Food groupings were determine based on their section placement in the Lower Mississippi Delta Nutrition Intervention Research Initiative Food Frequency Questionnaire (Delta NIRI FFQ).

\section{Cytokine data}

Participants underwent blood draws for inflammatory cytokines after an 8-hour overnight fast. Plasma was collected by members of the research team. Four panels of biomarkers were measured in plasma using singleplex or multiplex assays in a Luminex 200 platform. Measured biomarkers included those that have been linked to AD and family caregiver stress [20, 27, 28].

\section{Cognitive function data}

Cognitive testing was performed by trained, experienced and qualified research assistants. This study evaluated global and executive function, using 
the Montreal Cognitive Assessment (MoCA), the Reverse Corsi task (Corsi), the Trails Making Task (TMT), and the D-KEFS Tower Test. Widelyaccepted methods of reporting the data for each assessment were employed, including raw scores and scaled scores based on age norms when appropriate [29].

MoCA is a global cognitive screening tool for mild cognitive impairment [30]. It includes eight cognitive domains assessing clock drawing and 3-D cube copy task, TMT B task, phonemic fluency task, two-item verbal abstraction task, sustained attentional task, serial subtraction task, naming task, repetition of sentence task, and orientation to time and place task. Throughout the assessment, a score is given out of 30. One point is added for those with less than 12 years of education. A score greater than or equal to 26 is considered normal [30]. This is based on previous research which found that a cutoff score of 26 detected $90 \%$ of MCI subjects. Several papers have found that the minimal clinically important difference (MCID) for the MoCA test is 2 points [31-33].

Corsi task assesses short-term and working memory using nonverbal analog. The task consists of a board containing nine cubes at fixed, pseudorandom positions. The blocks are labeled with numbers only visible to the experimenter. The experimenter taps a certain number of blocks, after which the participant has to tap this block sequence in the reverse order as presented. The block sequences gradually increase in length, and the score that is obtained is generally the number of correctly remembered sequences or the length of the longest sequence that was remembered correctly [34].

Tower Test assesses planning ability by having participants move five discs of different sizes on pegs in specific arrangements printed on cards that were presented by the administrator [35]. They were told to attempt to make the arrangement in the least amount of moves possible. The number of moves as well as time was recorded.

TMT assesses executive function, visual attention and task switching among participants. This task contains two parts: part A and part B. In TMT A, participants need to connect 25 numbered circles continuously in an ascending order. In TMT B, 13 numbers and 12 letters must be alternately connected in ascending numerical and alphabetical order. The test is terminated after 5 minutes even if not completed. Once complete, a difference score (TMT B TMT A) is calculated [36].

\section{Statistical analysis}

Descriptive analyses were used to assess demographics of the study population using $t$-tests or Fisher's exact tests. For outcome variables, data were tested for normality using the Shapiro-Wilks test. Based on normality tests and the type of data (continuous or ordinal), Mann-Whitney U tests or $t$ tests were utilized to assess the association between dietary fat intake and scores on cognitive tests (MoCA, Tower Test, Corsi, and TMT) or serum cytokine levels. All analyses were conducted using SAS (SAS version 9.4, 2013, SAS Institute, Cary, NC). Significance for all analyses was set at the 0.05 level. A point-biserial correlation was performed between TNF $\alpha$ and the classification of diet (high-fat/low-fat diet). Pearson correlations were performed between cytokines.

\section{RESULTS}

Twenty-six women with first degree parental history of $\mathrm{AD}(59.5 \pm 8.20$ years $)$ were included in the sample analyses. Participants in the high-fat group $(n=7)$ and low-fat group $(n=19)$ did not differ significantly in the following measures: education, quality of life, number of medications, age, number of falls, BMI, learning disabilities, comorbidities, level of exercise, marital status, occupation, and income (Table 2).

Regarding whether dietary fat consumption was associated with performance on cognitive tests, participants in the high-fat diet group performed better on the MoCA $\left(p=0.04 ; \eta^{2}=0.148\right)$ compared to the low-fat diet group (Table 3). However, there was no significant difference between the groups in performance on the TMT, Tower Test, and Corsi blocks test (Table 3).

Regarding the effect of dietary fat intake on plasma cytokine levels, individuals who consumed a high-fat diet exhibited increased plasma levels of TNF $\alpha$ compared to the low-fat diet group $(p=0.02 ; \eta 2=0.196)$ (Table 4). Further, a correlation was observed between TNF $\alpha$ and fat diet category $(r=0.44, p=0.024)$. There were no differences in any other plasma cytokine levels (CRP, IL-10, and IL-8) between the high-fat and low-fat groups. A significant positive correlation was observed between TNF $\alpha$ and high IL-10 concentration $(r=0.401, p=0.04)$. 
Table 2

Characteristics of 26 African-American Women with Parental History of AD

\begin{tabular}{|c|c|c|c|c|}
\hline & Overall (n (\%)) & High-Fat & Low-Fat & $P$ \\
\hline BMI $\left(\mathrm{kg} / \mathrm{m}^{2}\right)$ & $30.65(4.86)$ & $32.48(5.51)$ & $29.98(4.57)$ & 0.253 \\
\hline $\operatorname{Age}(y)$ & $59.5(8.20)$ & $55.57(5.38)$ & $60.95(8.67)$ & 0.141 \\
\hline Number of Medications & $5.85(4.24)$ & $6.43(5.09)$ & $5.63(4.02)$ & 0.680 \\
\hline Number of Falls & $0.583(0.88)$ & $0.714(0.78)$ & $0.529(0.94)$ & 0.650 \\
\hline Years of Education & $15.50(3.22)$ & $15.43(0.98)$ & $16.21(2.10)$ & 0.356 \\
\hline \multicolumn{5}{|l|}{ Occupation Status } \\
\hline Disabled & $3(11.54)$ & $1(14.29)$ & $2(10.53)$ & \multirow[t]{5}{*}{0.197} \\
\hline Retired & $11(42.31)$ & $1(14.29)$ & $10(52.63)$ & \\
\hline Unemployed/seeking employment & $2(7.69)$ & $0(0)$ & $2(10.53)$ & \\
\hline Work full-time & $7(26.92)$ & $4(57.14)$ & $3(15.79)$ & \\
\hline Work part-time & $3(11.54)$ & $1(14.29)$ & $2(10.53)$ & \\
\hline \multicolumn{5}{|l|}{ Type of Housing } \\
\hline House/Apartment/Condominium & $24(92.31)$ & $6(85.71)$ & $18(94.74)$ & \multirow[t]{2}{*}{0.473} \\
\hline Relatives Home & $2(7.69)$ & $1(14.29)$ & $1(5.26)$ & \\
\hline \multicolumn{5}{|l|}{ Income } \\
\hline$\$ 19,000$ or less & $5(19.23)$ & $2(28.57)$ & $3(15.79)$ & \multirow[t]{5}{*}{0.697} \\
\hline$\$ 20,000-\$ 39,000$ & $6(23.08)$ & $2(28.57)$ & $4(21.05)$ & \\
\hline$\$ 40,000-\$ 59,000$ & $8(30.77)$ & $1(14.29)$ & $7(36.84)$ & \\
\hline$\$ 60,000-\$ 79,000$ & $2(7.69)$ & $0(0)$ & $2(10.53)$ & \\
\hline$\$ 80,000$ or more & $5(19.23)$ & $2(28.57)$ & $3(15.79)$ & \\
\hline \multicolumn{5}{|l|}{ Marital Status } \\
\hline Married/partnered & $7(26.92)$ & $1(14.29)$ & $6(31.58)$ & \multirow[t]{4}{*}{0.430} \\
\hline Separated/Divorced & $12(46.15)$ & $3(42.86)$ & $9(47.37)$ & \\
\hline Single & $4(15.38)$ & $1(14.29)$ & $3(15.79)$ & \\
\hline Widowed & $3(11.54)$ & $2(28.57)$ & $1(5.26)$ & \\
\hline \multicolumn{5}{|l|}{ Education } \\
\hline Years of Education & $15.50(3.22)$ & $15.43(0.98)$ & $16.21(2.10)$ & 0.356 \\
\hline High school graduate/GED & $1(3.85)$ & $0(0)$ & $1(5.26)$ & \multirow[t]{6}{*}{0.086} \\
\hline Vocational training & $2(7.69)$ & $2(28.57)$ & $0(0)$ & \\
\hline Some college/associate's degree & $4(15.38)$ & $0(0)$ & $4(21.05)$ & \\
\hline Bachelor's Degree (BA, BS) & $13(50)$ & $5(71.43)$ & $8(42.11)$ & \\
\hline Master's degree (or other post-graduate training) & $4(15.38)$ & $0(0)$ & $6(21.05)$ & \\
\hline Doctoral degree (PhD, MD, EdD, DDS, JD, etc.) & $2(7.69)$ & $0(0)$ & $2(10.53)$ & \\
\hline \multicolumn{5}{|l|}{ Exercise Activity } \\
\hline Never & $2(7.69)$ & $0(0)$ & $2(7.69)$ & \multirow[t]{5}{*}{0.932} \\
\hline Once a month & $2(7.69)$ & $1(14.29)$ & $1(3.85)$ & \\
\hline $1-4$ times per month & $6(23.08)$ & $2(28.57)$ & $4(15.38)$ & \\
\hline Greater than once a week & $15(57.69)$ & $4(57.14)$ & $11(57.89)$ & \\
\hline Don't know & $1(3.85)$ & $0(0)$ & $1(5.26)$ & \\
\hline \multicolumn{5}{|l|}{ Smoker } \\
\hline Yes & $7(26.92)$ & $3(42.86)$ & $8(42.11)$ & \multirow[t]{2}{*}{1} \\
\hline No & $19(73.08)$ & $4(57.14)$ & $11(57.89)$ & \\
\hline \multicolumn{5}{|l|}{ Alcohol in the past month } \\
\hline Yes & $7(26.92)$ & $1(14.29)$ & $12(63.16)$ & \multirow[t]{2}{*}{0.375} \\
\hline No & $19(73.08)$ & $6(85.71)$ & $7(36.84)$ & \\
\hline High Cholesterol & & & & \\
\hline No & $8(30.77)$ & $3(42.86)$ & $5(26.32)$ & 0.301 \\
\hline Yes & $16(61.54)$ & $3(42.86)$ & $13(68.42)$ & \\
\hline Unsure & $2(7.69)$ & $1(14.29)$ & $1(5.26)$ & \\
\hline Have you ever been told you have high blood pressu & & & & \\
\hline Yes & $18(62.23)$ & $4(57.14)$ & $14(73.68)$ & 0.635 \\
\hline No & $8(30.77)$ & $3(42.86)$ & $5(26.32)$ & \\
\hline Do you have diabetes? & & & & \\
\hline Yes & $5(19.23)$ & $1(14.29)$ & $4(21.05)$ & 1 \\
\hline No & $19(73.08)$ & $6(85.71)$ & $13(68.42)$ & \\
\hline Unsure & $2(7.69)$ & $0(0)$ & $2(10.53)$ & \\
\hline In general, how would you rate your quality of life? & & & & \\
\hline Low & $2(7.69)$ & $2(28.57)$ & $0(0)$ & 0.068 \\
\hline Moderate & $13(50)$ & $3(42.86)$ & $10(52.63)$ & \\
\hline High & $9(34.62)$ & $2(28.57)$ & $7(36.84)$ & \\
\hline Very High & $2(7.69)$ & $0(0)$ & $2(10.53)$ & \\
\hline
\end{tabular}

Independent $t$-tests (Mean $\pm \mathrm{SD}$ ) or Fisher's exact tests $(\mathrm{n}(\%))$ were used to determine significant differences between groups. 
Table 3

Cognitive performance of 26 African-American Women with Parental History of AD

\begin{tabular}{lcccc}
\hline Variable & & $M(S D)$ & $\eta^{2}$ & $P$ \\
\hline MoCA (/30) & Low-fat Intake & $24.7(2.7)$ & $0.148^{\S}$ & $0.04^{\dagger}$ \\
& High-fat Intake & $27.0(2.2)$ & & \\
Tower Test (total & Low-fat Intake & $9.6(2.3)$ & 0.002 & 0.81 \\
achievement score) & High-fat Intake & $9.9(1.4)$ & & \\
TMT Diff. (s) & Low-fat Intake & $50.3(23.3)$ & 0.025 & $0.34^{\dagger}$ \\
(Trails B - A) & High-fat Intake & $41.8(28.0)$ & & \\
Corsi (number of & Low-fat Intake & $9.6(2.3)$ & 0.002 & 0.81 \\
correct trials) & High-fat Intake & $9.9(1.4)$ & & \\
\hline
\end{tabular}

$M$, mean; $S D$, standard deviation. ${ }^{\S}$ Moderate effect size according to partial eta squared. ${ }^{\dagger} p$-values determined with Mann-Whitney $\mathrm{U}$ test.

Table 4

Inflammatory Variables of 26 African-American Women with Parental History of AD

\begin{tabular}{llccc}
\hline Variable & & $M(S D)$ & $\eta^{2}$ & $P$ \\
\hline TNF $\alpha$ & Low-fat diet & $5.17(1.3)$ & $0.196^{\S}$ & 0.02 \\
& High-fat diet & $6.82(2.0)$ & & \\
CRP^ & Low-fat diet & $0.394(0.52)$ & 0.000 & $0.69^{\dagger}$ \\
& High-fat diet & $0.371(0.35)$ & & \\
IL-10 & Low-fat diet & $10.96(5.41)$ & 0.002 & $0.62^{\dagger}$ \\
& High-fat diet & $11.47(4.37)$ & & \\
IL-8 & Low-fat diet & $16.51(38.18)$ & 0.028 & $0.56^{\dagger}$ \\
& High-fat diet & $4.24(2.02)$ & & \\
\hline
\end{tabular}

$M$, mean; $S D$, standard deviation; IL, Interleukin; CRP, C-reactive protein; TNF $\alpha$, Tumor necrosis factor alpha; $\eta^{2}$, partial effect size. ${ }^{\dagger} p$-values determined with Mann-Whitney $\mathrm{U}$ test. ^ measured in $\mathrm{ng} / \mathrm{mL}$, all others measured in $\mathrm{pg} / \mathrm{mL}$.

\section{DISCUSSION}

This study demonstrated better global cognition and higher plasma $\mathrm{TNF} \alpha$ levels in AA women with a family history of AD who consume a high-fat diet compared to a low-fat diet. While changes in global cognition were found between dietary fat groups, there were no significant differences in performance on other measures of cognitive function, including the Corsi, Tower Test, and the TMT.

Performance on cognitive tasks between the dietary fat groups contradicted the original hypothesis that higher fat intake results in decreased cognitive ability. Participants who consumed a high-fat diet performed better on the MoCA ( $\sim 27$ points) compared to those with a lower intake of dietary fat $(\sim 25$ points). A cut-off score of 26 is typically used to diagnose MCI with $90 \%$ accuracy [30]. Using this cutoff, individuals consuming a low-fat diet would be considered having an MCI compared to high-fat diet. Further, the mean difference between the high- fat diet and the low-fat diet is 2.32. This is higher than the reported MCID (2 points) for the MoCA indicating a difference in clinical treatment and functional meaning between the two groups. While no statistical difference was observed between nutrition groups for TMT, our findings may be clinically relevant. A study examined well-educated (education $=12-19$ years), community-dwelling residents with no CNS trauma, alcohol abuse, or cardiac problems [37]. 105 females (45 years of age or older) performed an average TMT difference of $39.6 \mathrm{~s}$ based on averaging subtracted means (B-A). Based on these values, only a slight impairment was observed for the high-fat diet group (41.8 s), but the low-fat group exhibited a more considerable impairment (50.3 s). As a result, this may indicate mild cognitive impairment in abilities such as working memory, executive function, and cognitive flexibility. Deficiencies in these areas may impair everyday normative functions such as driving which requires moderate cognitive flexibility.

This finding raises new questions about the role of diet and cognitive function. Researchers have often examined the role of nutrition on global cognition, yet present contrasting conclusions. These differing conclusions could be due to varying fatty acid profiles within the diet. For example, a prospective cohort study from 1988-2016 found that adhering to a Mediterranean diet or a plant based polyunsaturated fatty acid diet increases global cognitive function and executive function support [38]. Whereas another prospective cohort, a higher intake of a Western style diet (typically higher in saturated fats) was correlated with worse cognitive performance on visual spatial learning, long-term memory, and reaction time tasks [39]. While the exact composition of saturated and unsaturated fats was not calculated in this paper, our data suggests that a high-fat diet can be beneficial for cognition. Similar findings have been found in rodents on a ketogenic diet that was high in fats [40].

Elevated levels of the proinflammatory cytokine $\mathrm{TNF} \alpha$ were observed in the plasma for individuals eating a high-fat diet compared to low-fat diet. These results replicate previous findings that a high-fat diet increases the amount of TNF $\alpha$ present in the plasma [21]. Further, this study found that levels of TNF $\alpha$ correlated with IL-10, an anti-inflammatory cytokine. The increase in an anti-inflammatory cytokine might be in response to the increase in TNF $\alpha$.

This study had several limitations. This study was underpowered therefore the results should be interpreted cautiously. Specifically, the ability to detect significant correlations was limited due to 
the small sample sizes. However, it is important to disseminate the results of this pilot study to begin to build a foundation of knowledge regarding this unique, underserved and understudied population. Furthermore, USDA Food Composition Database was temporarily affected by political factors and not updated regularly. This lapse may have affected the total fat average on the various food options which was used to compute the overall fat score. Another limitation is that this study did not categorize fat intake by saturated or unsaturated fats. Previous research has shown the difference that fatty acids can have on cognition $[38,39]$ and cytokine levels [21]. Many of the high fat foods listed were high in saturated fats, with the exception of the omega 3 supplement. This study did not specifically consider the omega 3 supplement's impact on fat content or cognitive status. It is possible that taking an omega 3 supplement alone is associated with better cognitive function. Future studies should investigate the interrelationship of cognitive function with omega 3 and fat intake. Caregiver status was also not considered. Caregiver status may influence inflammatory variables measured. Many studies have suggested a link between family caregiving and adverse mental and physical health consequences. However, family caregiving may also have positive effects on health and well-being. Several populationbased studies have found longer lifespans for family caregivers compared to individuals who did not have family caregiver responsibilities [41]. However, AD caregiving is associated with higher levels of subjective stress measures, as well as elevated levels of C-reactive protein and inflammatory cytokines [27, 28].

$\mathrm{AD}$ is the most prevalent age-related neurodegenerative disease and is clinically characterized by a progressive loss of memory and other cognitive functions. Although it is difficult to identify which environmental factors induce $\mathrm{AD}$ and other dementia-based disorders, it is important to take preventative measures to delay cognitive impairments in high-risk individuals. Deficits in cognition lead to impairments in everyday activities, which require processes involved in reasoning, synthesis and problem-solving. In this study, we rejected the original hypothesis that consuming a high-fat diet would cause cognitive impairments. Yet, it is interesting to note that nutrition science often has various conflicting information involved in what affects the human body. Nutritional evidence-based science data often reverse or contradict one another over time. This may explain why we saw more prominent cognitive deficits in the low-fat consumption group. Ultimately, this is a pilot study to power future studies involved in nutrition and cognitive function. By understanding which dietary modifications are needed to delay or mitigate the onset of $\mathrm{AD}$, more nutritional based programs can be implemented. Subsequently, diet and nutrition-based interventions for those at risk for developing $\mathrm{AD}$ may result in decreasing mortality rates linked to $\mathrm{AD}$, especially in regions where nutrition influences culture.

\section{ACKNOWLEDGMENTS}

A Department of Veterans Affairs Career Development award supported ME Hackney (N0780W). This trial was supported by a pilot grant from the Emory Goizueta Alzheimer's Disease Research Center and the Atlanta VA Center for Visual and Neurocognitive Rehabilitation. The Emory Center for Health in Aging supplied space and resources.

\section{CONFLICT OF INTEREST}

The authors have no conflicts of interest to report.

\section{REFERENCES}

[1] (2020) 2020 Alzheimer's disease facts and figures. Alzheimers Dement, doi: 10.1002/alz.12068.

[2] Walsh DM, Teplow DB (2012) Alzheimer's disease and the amyloid beta-protein. Prog Mol Biol Transl Sci 107, 101124.

[3] Brookmeyer R, Johnson E, Ziegler-Graham K, Arrighi HM (2007) Forecasting the global burden of Alzheimer's disease. Alzheimers Dement 3, 186-191.

[4] Sibener L, Zaganjor I, Snyder HM, Bain LJ, Egge R, Carrillo MC (2014) Alzheimer's Disease prevalence, costs, and prevention for military personnel and veterans. Alzheimers Dement 10, S105-110.

[5] Ridge PG, Ebbert MT, Kauwe JS (2013) Genetics of Alzheimer's disease. Biomed Res Int 2013, 254954.

[6] Fladby T, Palhaugen L, Selnes P, Waterloo K, Brathen G, Hessen E, Almdahl IS, Arntzen KA, Auning E, Eliassen CF, Espenes R, Grambaite R, Grontvedt GR, Johansen KK, Johnsen SH, Kalheim LF, Kirsebom BE, Muller KI, Nakling AE, Rongve A, Sando SB, Siafarikas N, Stav AL, Tecelao S, Timon S, Bekkelund SI, Aarsland D (2017) Detecting at-risk Alzheimer's disease cases. J Alzheimers Dis 60, 97-105.

[7] Chin AL, Negash S, Hamilton R (2011) Diversity and disparity in dementia: The impact of ethnoracial differences in Alzheimer disease. Alzheimer Dis Assoc Disord 25, 187195.

[8] Mielke MM, Vemuri P, Rocca WA (2014) Clinical epidemiology of Alzheimer's disease: Assessing sex and gender differences. Clin Epidemiol 6, 37-48.

[9] Scarabino D, Gambina G, Broggio E, Pelliccia F, Corbo RM (2016) Influence of family history of dementia in the devel- 
opment and progression of late-onset Alzheimer's disease. Am J Med Genet B Neuropsychiatr Genet 171B, 250-256.

[10] Donix M, Small GW, Bookheimer SY (2012) Family history and APOE-4 genetic risk in Alzheimer's disease. Neuropsychol Rev 22, 298-309.

[11] Wolters FJ, van der Lee SJ, Koudstaal PJ, van Duijn CM, Hofman A, Ikram MK, Vernooij MW, Ikram MA (2017) Parental family history of dementia in relation to subclinical brain disease and dementia risk. Neurology $\mathbf{8 8}$, 1642-1649.

[12] Ritchie K, Carriere I, Su L, O’Brien JT, Lovestone S, Wells K, Ritchie CW (2017) The midlife cognitive profiles of adults at high risk of late-onset Alzheimer's disease: The PREVENT study. Alzheimers Dement 13, 1089-1097.

[13] Lee JE, Shin DW, Jeong SM, Son KY, Cho B, Yoon JL, Park BJ, Kwon IS, Lee J, Kim S (2018) Association between Timed Up and Go Test and future dementia onset. J Gerontol A Biol Sci Med Sci 73, 1238-1243.

[14] Theriault P, ElAli A, Rivest S (2016) High fat diet exacerbates Alzheimer's disease-related pathology in APPswe/PS1 mice. Oncotarget 7, 67808-67827.

[15] Alwarawrah Y, Kiernan K, MacIver NJ (2018) Changes in nutritional status impact immune cell metabolism and function. Front Immunol 9, 1055.

[16] Cao W, Zheng H (2018) Peripheral immune system in aging and Alzheimer's disease. Mol Neurodegener 13, 51.

[17] Tan ZS, Beiser AS, Vasan RS, Roubenoff R, Dinarello CA, Harris TB, Benjamin EJ, Au R, Kiel DP, Wolf PA, Seshadri S (2007) Inflammatory markers and the risk of Alzheimer disease: The Framingham Study. Neurology 68, 1902-1908.

[18] Cunningham C (2011) Systemic inflammation and delirium: Important co-factors in the progression of dementia. Biochem Soc Trans 39, 945-953.

[19] Chang R, Yee KL, Sumbria RK (2017) Tumor necrosis factor alpha Inhibition for Alzheimer's disease. J Cent Nerv Syst Dis 9, 1179573517709278.

[20] Michaud M, Balardy L, Moulis G, Gaudin C, Peyrot C, Vellas B, Cesari M, Nourhashemi F (2013) Proinflammatory cytokines, aging, and age-related diseases. J Am Med Dir Assoc 14, 877-882.

[21] Lennie TA, Chung ML, Habash DL, Moser DK (2005) Dietary fat intake and proinflammatory cytokine levels in patients with heart failure. J Card Fail 11, 613-618.

[22] Han SN, Leka LS, Lichtenstein AH, Ausman LM, Schaefer EJ, Meydani SN (2002) Effect of hydrogenated and saturated, relative to polyunsaturated, fat on immune and inflammatory responses of adults with moderate hypercholesterolemia. J Lipid Res 43, 445-452.

[23] Kim MS, Choi MS, Han SN (2011) High fat diet-induced obesity leads to proinflammatory response associated with higher expression of NOD2 protein. Nutr Res Pract 5, 219223.

[24] Hackney ME, McCullough LE, Bay AA, Silverstein HA, Hart AR, Shin RJ, Wharton W (2019) Rationale and design of a clinical trial of adapted tango to improve negative health impacts in middle aged African-American female caregivers of persons with Alzheimer's disease (ACT Trial). J Alzheimers Dis 68, 767-775.

[25] Tucker KL, Maras J, Champagne C, Connell C, Goolsby S, Weber J, Zaghloul S, Carithers T, Bogle ML (2005) A regional food-frequency questionnaire for the US Mississippi Delta. Public Health Nutr 8, 87-96.

[26] Carithers TC, Talegawkar SA, Rowser ML, Henry OR, Dubbert PM, Bogle ML, Taylor HA, Jr., Tucker KL (2009) Validity and calibration of food frequency questionnaires used with African-American adults in the Jackson Heart Study. J Am Diet Assoc 109, 1184-1193.

[27] Aschbacher K, von Kanel R, Mills PJ, Hong S, Roepke SK, Mausbach BT, Patterson TL, Ziegler MG, Dimsdale JE, Ancoli-Israel S, Grant I (2007) Combination of caregiving stress and hormone replacement therapy is associated with prolonged platelet activation to acute stress among postmenopausal women. Psychosom Med 69, 910-917.

[28] Gouin JP, Glaser R, Malarkey WB, Beversdorf D, KiecoltGlaser J (2012) Chronic stress, daily stressors, and circulating inflammatory markers. Health Psychol 31, 264268.

[29] Delis DC, Kramer JH (2001) Delis-Kaplan Executive Function System: Technical Manual. Harcourt Assessment Company.

[30] Nasreddine ZS, Phillips NA, Bedirian V, Charbonneau S, Whitehead V, Collin I, Cummings JL, Chertkow H (2005) The Montreal Cognitive Assessment, MoCA: A brief screening tool for mild cognitive impairment. J Am Geriatr Soc 53, 695-699.

[31] Wu CY, Hung SJ, Lin KC, Chen KH, Chen P, Tsay PK (2019) Responsiveness, minimal clinically important difference, and validity of the MoCA in stroke rehabilitation. Occup Ther Int 2019, 2517658.

[32] Wong GKC, Mak JSY, Wong A, Zheng VZY, Poon WS, Abrigo J, Mok VCT (2017) Minimum clinically important difference of Montreal Cognitive Assessment in aneurysmal subarachnoid hemorrhage patients. J Clin Neurosci 46, 4144.

[33] Nasreddine ZS, Patel BB (2016) Validation of Montreal Cognitive Assessment, MoCA, alternate French versions. Can J Neurol Sci 43, 665-671.

[34] Kessels RP, van den Berg E, Ruis C, Brands AM (2008) The backward span of the Corsi Block-Tapping Task and its association with the WAIS-III Digit Span. Assessment 15, 426-434.

[35] Michalec J, Bezdicek O, Nikolai T, Harsa P, Jech R, Silhan P, Hyza M, Ruzicka E, Shallice T (2017) A comparative study of Tower of London scoring systems and normative data. Arch Clin Neuropsychol 32, 328-338.

[36] Arbuthnott K, Frank J (2000) Trail making test, part B as a measure of executive control: Validation using a setswitching paradigm. J Clin Exp Neuropsychol 22, 518-528.

[37] Elias MF, Robbins MA, Walter LJ, Schultz NR Jr (1993) The influence of gender and age on Halstead-Reitan neuropsychological test performance. J Gerontol 48, P278-281.

[38] Richard EL, Laughlin GA, Kritz-Silverstein D, Reas ET, Barrett-Connor E, McEvoy LK (2018) Dietary patterns and cognitive function among older community-dwelling adults. Nutrients 10, 1088.

[39] Nyaradi A, Li J, Hickling S, Foster J, Oddy WH (2013) The role of nutrition in children's neurocognitive development, from pregnancy through childhood. Front Hum Neurosci 7, 97.

[40] Hernandez AR, Hernandez CM, Campos K, Truckenbrod L, Federico Q, Moon B, McQuail JA, Maurer AP, Bizon JL, Burke SN (2018) A ketogenic diet improves cognition and has biochemical effects in prefrontal cortex that are dissociable from hippocampus. Front Aging Neurosci 10, 391.

[41] Roth DL, Sheehan OC, Haley WE, Jenny NS, Cushman M, Walston JD (2019) Is family caregiving associated with inflammation or compromised immunity? A meta-analysis. Gerontologist 59, e521-e534. 